\title{
Laparoscopic intraperitoneal onlay mesh for pediatric incisional hernia-a case report
}

\author{
Maho Inoue*, Shigeyoshi Aoi, Akihiro Taniguchi, Kohei Sakai, Mayumi Higashi, Shigehisa Fumino, \\ Taizo Furukawa and Tatsuro Tajiri
}

\begin{abstract}
Background: The incidence of incisional hernia in pediatric patients is low in comparison with that reported in adults. In the pediatric population, primary closure has generally been favored. However, synthetic or biomedical mesh offers advantages in the repair of larger defects when primary closure is difficult. The use of laparoscopic intraperitoneal onlay mesh (IPOM) in the adult population has been well documented. In the pediatric population, a few laparoscopic approaches with direct suturing have been proposed; however, there are no reports of laparoscopic repair with the use of IPOM.

Case presentation: The patient was a 1-year-old girl with epigastric incisional hernia after an operation to correct a complete arteriovenous septal defect. The fascial defect (size $30 \times 35 \mathrm{~mm}$ ) was large; thus, direct suturing was considered to be associated with a high risk of thoracic deformation and recurrence.

Laparoscopic IPOM was performed. The fascial defect was detected precisely through the laparoscopy, and non-absorbable mesh was placed through a 12-mm trocar. Minimal incisions were required for the trocars, and extensive dissection of the abdominal wall structure was not needed. This procedure allowed for the integrity and functional status of the abdominal wall to be maintained.

Conclusion: Laparoscopic IPOM is a minimally invasive and cosmetically acceptable method that can be applied to the treatment of large incisional hernias in children.
\end{abstract}

Keywords: Incisional hernia, Laparoscopic surgery, Intra peritoneal onlay mesh, Pediatric surgery

\section{Background}

The incidence of incisional hernia among children undergoing primary abdominal surgery at $<6$ months of age is reported to be $2.3 \%$ [1]. This incidence is low in comparison with that reported in adults (10-50\%) [2]. In the pediatric population, primary closure has generally been favored. A few laparoscopic approaches with direct suturing have been proposed $[3,4]$; however, there have been no reports of laparoscopic repair with the use of mesh in the pediatric population. Direct repair without mesh is associated with high rates of recurrence in adults (direct suture, 12-54\%; tension-free repair, 2-36\%) [5]. Thus, the use of mesh reinforcement has been encouraged to relieve tension on the fascial repair

\footnotetext{
* Correspondence: maho-i@koto.kpu-m.ac.jp

Department of Pediatric Surgery, Kyoto Prefectural University of Medicine, 465 Hirokoji-Kamigyoku, Kyoto 602-8566, Japan
}

$[6,7]$. The application of laparoscopic intraperitoneal onlay mesh (IPOM) procedures in adult patients has been well documented. In the present study, we describe the use of laparoscopic IPOM in the treatment of a 1-year-old girl with a large epigastric incisional hernia after corrective surgery to treat a complete arteriovenous septal defect.

\section{Case presentation}

The patient was a 1-year-old girl with trisomy 21 who was diagnosed with complete arteriovenous septal defect (cAVSD) at birth and who had undergone pulmonary artery banding and ligation of the patent ductus arteriosus at 42 days of age. cAVSD repair and pulmonary artery debanding and plasty were performed 1 year later. A bulge in the epigastric abdominal wall was noticed after these operations. The patient had no history of
Springer Open

(c) The Author(s). 2017 Open Access This article is distributed under the terms of the Creative Commons Attribution 4.0 International License (http://creativecommons.org/licenses/by/4.0/), which permits unrestricted use, distribution, and reproduction in any medium, provided you give appropriate credit to the original author(s) and the source, provide a link to the Creative Commons license, and indicate if changes were made. 

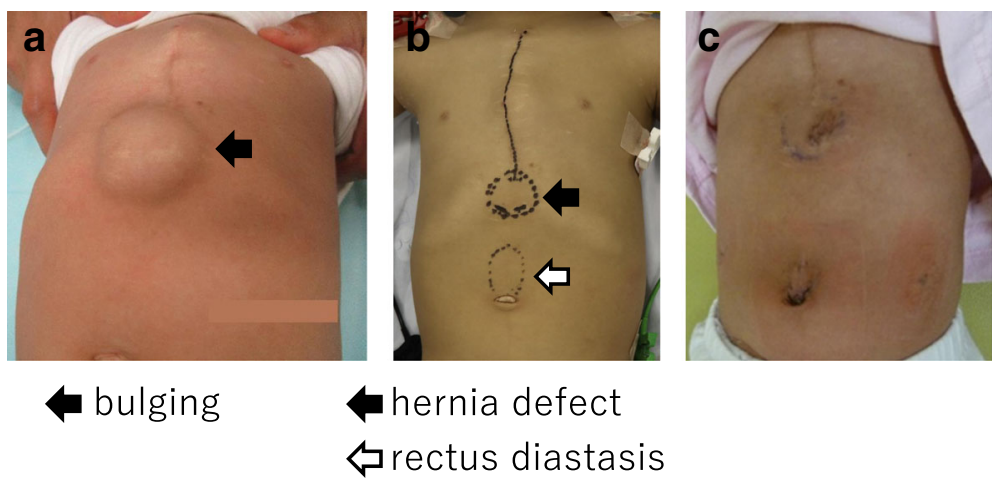

Fig. 1 The physical examinations before $(\mathbf{a}, \mathbf{b})$ and after $(\mathbf{c})$ the operation. The hernia defect measured $30 \times 35 \mathrm{~mm}$, located on $5 \mathrm{~mm}$ caudal to the xiphoid process. The rectal diastasis, which was detected $5 \mathrm{~mm}$ cranial to the umbilicus, is marked (b)

incarceration. An abdominal protrusion measuring $30 \times$ $35 \mathrm{~mm}$ in size was located $5 \mathrm{~mm}$ caudal to the xiphoid process when the patient was in a supine position (Fig. 1). An intra-umbilical incision was made, and a 3-mm trocar was inserted. Pneumoperitoneum $(8 \mathrm{mmHg})$ was maintained using carbon dioxide insufflation. A 3-mm $30^{\circ}$ laparoscope was introduced, and the abdominal wall was inspected. Three-millimeter trocars were inserted in the bilateral flank, as shown in Fig. 2b. The fascial defect was exposed by the left side of the falciform ligament of the liver as shown in Fig. 3a. The falciform ligament was incised to create an adequate space for the placement of the mesh, as shown in Fig. 3c. The size of the mesh was decided based on the size of the hernia orifice, with $2.5 \mathrm{~cm}$ of extra coverage on each side. We applied an $8.0 \times 8.0 \mathrm{~cm} \mathrm{Bard}^{\circ}$ Ventralrex ${ }^{\circ} \mathrm{ST}(\mathrm{L})$, which was coated with hyaluronic acid sodium and carboxy methyl cellulose. A $12-\mathrm{mm}$ ENDOPATH ${ }^{\oplus} \mathrm{XCEL}$ BLADLESS trocar was inserted into the hernia orifice, and rolled-up mesh was inserted through the trocar as shown in Fig. 4. After extracting the trocar, the mesh was unrolled and placed on the hernia defect intraperitoneally, while pulling the strap against the abdominal wall. Through the extended first umbilical incision, the rectus diastasis was closed using the open method, and the caudal part of the mesh was sutured directly to the fascia at the same time. Fixation methods (include the use of tackers or percutaneous suture fixation) were not applied to avoid pneumothorax and vascular injuries. The recovery was uneventful. Oral feeding was started on postoperative day 2. The patient was discharged on postoperative day 6 . There has been no evidence of recurrence or complications in the 2 months since surgery.

\section{Discussion}

The IPOM technique allows for the placement of a large mesh through a 12-mm-diameter working port to cover a hernia defect with an adequate mesh margin. The intraperitoneal placement of the mesh intraperitoneally avoids extensive tissue dissection. As a result, IPOM reduces the chance of surgical-site infection [8]. This technique, which does not require a major abdominal a

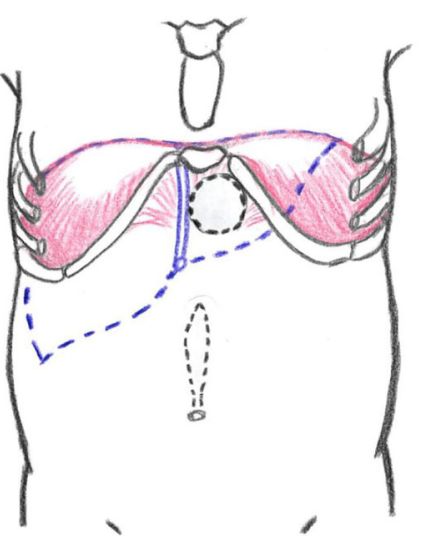

b

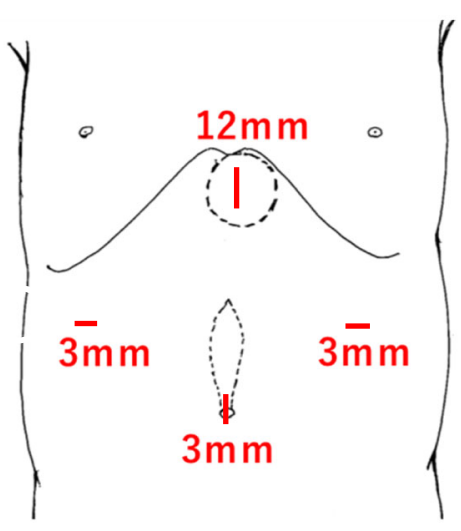

Fig. 2 The location of the defect and port setting. The defect was adjacent to the diaphragm; the liver was located just under the defect (a). In total, four ports were placed in the abdomen (b) 

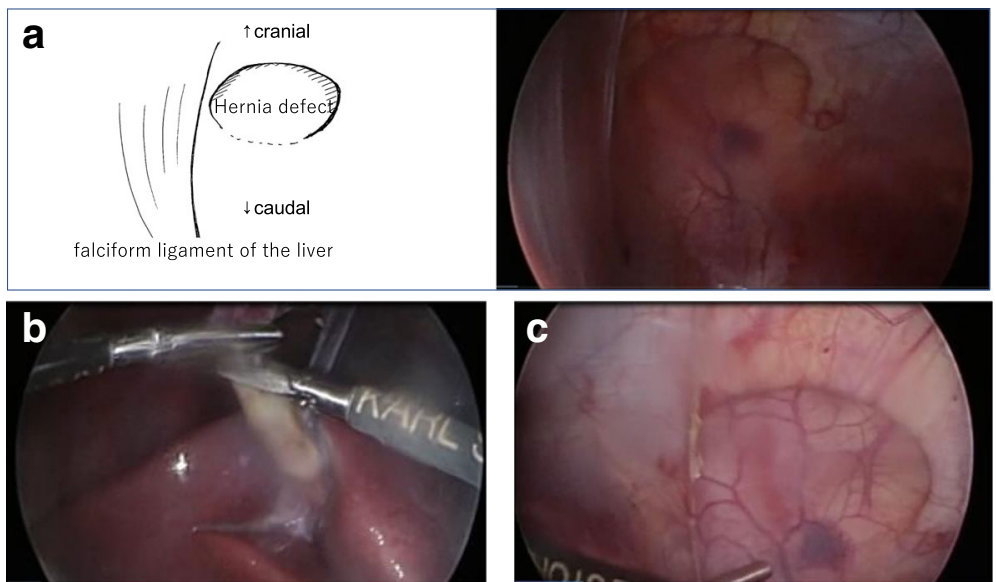

Fig. 3 Exposure of the hernia defect. The fascial defect was adjacent to the falciform ligamentum of the liver (a). The falciform ligamentum was incised with scissors after coagulation (b, c)

incision, allows for the integrity and the functional status to be maintained. A hernia defect of $>10 \mathrm{~cm}$ in size is a significant risk factor for recurrence according to the adult guidelines [8]. In our case, the risk of recurrence was assumed to be high because the $30 \times 35 \mathrm{~mm}$ defect in the $8-\mathrm{kg}$ patient was considered to be large relative to an adult of $60 \mathrm{~kg}$ in body weight. Moreover, it was likely that direct suturing would have caused thoracic deformation and compression of the heart. Thus, mesh repair was finally performed. A Bard $^{\circ}$ Ventralrex ${ }^{\circ} \mathrm{ST}$ mesh, which has a strap for pulling up and fixing the mesh to the abdominal wall, was applied. Traction, which was applied using the strap, and the recoiling polydioxanone structure of the mesh provided complete expansion. One of greatest merits of laparoscopic surgery in pediatric cases is that the magnified view helps in deciding the best treatment when the objective is too small to approach directly. In terms of complications, cases of iatrogenic enterotomy, which is associated with the need for extensive adhesiolysis, have been reported [9]. Many studies have noted that mesh-induced visceral complications, which include adhesion, fistulation, and migration of the mesh, should be considered to be very important postoperative concerns [10]. Although various types of meshes have been developed, none has been able to completely suppress tissue reactions [11]. In this case, the risk of adhesion to the intestine was not considered highly, because the liver was located just below the mesh. The preperitoneal onlay mesh (PPOM) repair, dissecting extraperitoneally, has been reported in adult cases in these days [12]. Although, to eliminate the visceral organ's adverse chronic reactions to the synthetic mesh, placing synthetic mesh in
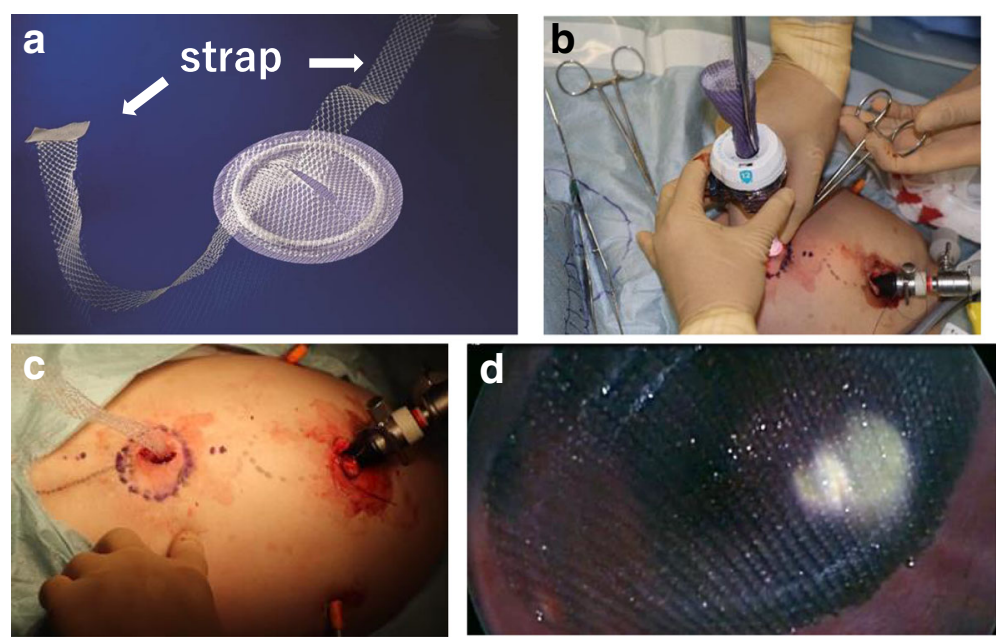

Fig. 4 Mesh insertion and placement. A rolled-up $8.0 \times 8.0 \mathrm{~cm}$ Bard ${ }^{\oplus}$ Ventralrex ${ }^{\oplus} \mathrm{ST}(\mathrm{L})$ was inserted through a 12-mm ENDOPATH®XCEL BLADLESS trocar $(\mathbf{a}, \mathbf{b})$. While the strap pulling the strap against the abdominal wall after extracting the trocar $(\mathbf{c})$, the mesh was unrolled and placed on the hernia defect intraperitoneally (d) 
the preperitoneal place may be ideal, the creation of the preperitoneal pocket for mesh placement might be technically complicated and time-consuming in the pediatric small abdominal cavity like this case. It is difficult to know the exact biological processes that occur as a result of the long-term placement of the mesh in the peritoneal cavity of infants. For example, multiple studies have shown that patients who undergo congenital diaphragmatic hernia repair with a prosthetic patch have an increased incidence of chest wall deformities [13-15]. Long-term follow-up is recommended to ascertain how the mesh affects development.

\section{Conclusions}

Laparoscopic IPOM is minimally invasive and cosmetically acceptable method for repairing large incisional hernias in children.

\section{Abbreviations}

CAVSD: Complete arteriovenous septal defect; IPOM: Intraperitoneal onlay mesh

\section{Funding}

This research did not receive any specific grants from funding agencies in the public, commercial, or not-for-profit sectors.

\section{Authors' contributions}

$\mathrm{Ml}$ drafted the manuscript, and TT supervised the writing of the manuscript YA performed the preoperative ultrasonography. MI, AT, and SA performed the perioperative management of the patient. MI, AT, and SA performed the operation. SA supervised the management of the patient. All authors read and approved the final manuscript.

\section{Ethics approval and consent to participate}

Not applicable

\section{Consent for publication}

Written informed consent was obtained from the family of the patient for the publication of this case report.

\section{Competing interests}

The authors declare that they have no competing interests.

\section{Publisher's Note}

Springer Nature remains neutral with regard to jurisdictional claims in published maps and institutional affiliations.

Received: 17 October 2017 Accepted: 29 November 2017

Published online: 07 December 2017

\section{References}

1. Mullassery D, Pedersen A, Robb A, et al. Incisional hernia in pediatric surgery-experience at a single UK tertiary centre. J Pediatr Surg. 2016;51:1791-4.

2. Itatsu K, Yokoyama Y, Sugawara G, et al. Incidence of and risk factors for incisional hernia after abdominal surgery. Br J Surg. 2014;101:1439-47.

3. Albanese $C T$, Renqal $S$, Bermudez D. A novel laparoscopic technique for the repair of pediatric umbilical and epigastric hernias. J Pediatr Surg. 2006;41:859-62.

4. Moreira-Pinto J, Correia-Pinto J. Scarless laparoscopic repair of epigastric hernia in children. Hernia. 2015;19:623-6.

5. Zhang Y, Zhou H, Chai Y, et al. Laparoscopic versus open Incisional and ventral hernia repair: a systematic review and meta-analysis. World I Surg. 2014;38:2233-40.

6. Natarajan S, Meenaa S, Thimmaiah KA. A randomised prospective study to evaluate preperitoneal mesh repair versus onlay mesh repair and laparoscopic IPOM in incisional hernia surgery. Indian J Surg. 2017:79:96-100.

7. Heniford BT, Park A, Ramshaw BJ, et al. Laparoscopic repair of ventral hernias nine years' experience with 850 consecutive hernias. Ann Surg. 2003;238:391-9.
8. Bittner R, Bingener-Casey J, Dietz $U$ et al. Guidelines for laparoscopic treatment of ventral and incisional abdominal wall hernias (International Endohernia Society (IEHS))_-part 1. Surg Endosc 2014; 28:2-29.

9. Bittner R, Bingener-Casey J, Dietz U et al: Guidelines for laparoscopic treatment of ventral and incisional abdominal wall hernias (International Endohernia Society (IEHS))_part 2. Surg Endosc 2014; 28:353-379.

10. Bittner R, Bingener-Casey J, Dietz $U$ et al: Guidelines for laparoscopic treatment of ventral and incisional abdominal wall hernias (International Endohernia Society (IEHS))_-part 3. Surg Endosc 2014; 28:380-404.

11. Siy RW, Pferdehirt RE, Izaddoost SA. Non-crosslinked porcine acellular dermal matrix in pediatric abdominal wall reconstruction: a case series. J Pediatr Surg. 2017;52:639-43.

12. George $P$, Cheung $Y$. From intraperitoneal onlay mesh repair to preperitoneal onlay mesh repair. Asian J Endosc Surg. 2017;10:119-27.

13. Kuklova P, Zemkova D, Kyncl M, et al. Large diaphragmatic defect: are skeletal deformities preventable? J Pediatr Surg. 2011;27:1343-9.

14. Jancelewicz T, Chiang M, Oliveira C, et al. Late surgical outcomes among congenital diaphragmatic hernia $(\mathrm{CDH})$ patients: why long-term follow-up with surgeons is recommended. J Pediatr Surg. 2013;48:935-41.

15. Russell KW, Bamhart DC, Rollins MD, et al. Musculoskeletal deformities following repair of large congenital diaphragmatic hernias. J Pediatr Surg. 2014:49:886-9.

\section{Submit your manuscript to a SpringerOpen ${ }^{\circ}$ journal and benefit from:}

- Convenient online submission

- Rigorous peer review

- Open access: articles freely available online

- High visibility within the field

- Retaining the copyright to your article

Submit your next manuscript at $>$ springeropen.com 